\title{
Influence of Assistive Technology in Attaining Sustainable Development Goal 3: An Indian Perspective
}

\author{
Ponmozhi Chezhiyan, K.Maheswari, P. Sriramakrishnan, S. Rakumar, Jyothi Kanagaraj
}

\begin{abstract}
World now tries to move on sustainable development. This means development of the current generation without affecting future generations' rights on environment, employability, healthy life. Towards this end United Nations drafted 17 Sustainable development goals to be achieved in the year 2030. Sustainable Development Goal 3, states that countries should "Ensure healthy lives and promote well-being for all persons with disabilities". Disabled persons will be in the marginal position in the society because of the disability. Disabled can be helped by assistive technology. Assistive technology will help in many ways, such as (i) assisting to live, or (ii) to have improvement in their disability, (iii) to assess the level of disability, (iv) to train disabled to overcome disability. This paper analyses the status of disabled in the India, various types of disabled persons with statistics, their condition in the society and the challenges in utilizing these devices for the upliftment of the disabled.
\end{abstract}

Keywords : Assisted Living, Assistive technology, Disability, Sustainable development.

\section{INTRODUCTION}

Sustainable development means meeting the needs of the current society without affecting the future generations' rights of living. And thus, the goal of Sustainable development is to attain development in all three dimensions namely economic, social and environment refer figure 1.

Sustainable development by United Nations [1] expects to end poverty, protect the environment and all people enjoy peace and poverty. The term "All people" includes people with disabilities. Among the total population of the world $10 \%$ of the Persons are with disabilities; of which $80 \%$ live in developing countries [2]. Based on the census 2011, Among 121 Corer of its population India has $2.21 \%$ which amounts to 2.68 Crore of person are disabled [3].

Revised Manuscript Received on December 16, 2019.

* Correspondence Author

Ponmozhi Chezhiyan *, Department of Computer Applications Kalasalingam Academy of Research and Eduaction Krishnankoil, Srivilliputhur, TamilNadu, India.Email: chezhiyan71.p@gmail.com

K. Maheswari, Department of Computer Applications, Kalasalingam Academy of Research and Education, Krishnankoil, Srivilliputhur Tamil Nadu, India Email:maheswarisnr@gmail.com

P. Sriramakrishnan, Department of Computer Applications, Kalasalingam Academy of Research and Eduaction Krishnankoil, Srivilliputhur, TamilNadu, India. Email: sriram0210@gmail.com

S. Rakumar , Department of Computer Applications, Kalasalingam Academy of Research and Eduaction Krishnankoil, Srivilliputhur, TamilNadu, India. Email: ramkumar.dr12013@gmail.com

Jyothi Kanagaraj, School of Bio and Chemical Engineering, Kalasalingam Academy of Research and Education, Krishnankoil, Tamil Nadu, India . Email: jyothi.k@klu.ac.in

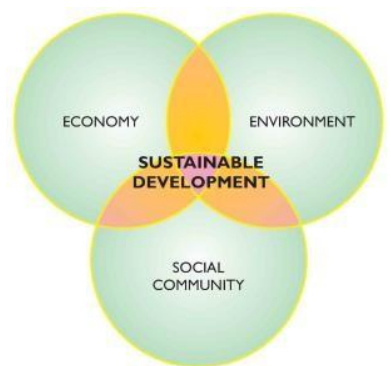

Figure 1: dimensions of sustainable development[Image Courtesy :

astriding.limehouse.co.uk/events/2359/images/highresRGB

$$
\text { / 163780_1_0.png] }
$$

Always people with disabilities will be marginalized due to their in ability to access services, resources and opportunities [4]. Disabled persons will have lower education achievements; also their financial contribution to the family is less compared to others [5]. Disabled children are deprived of education opportunities, and they will be facing inequality treatment [6]. As per the report of UNESCO, the literacy rate of women and children with disabilities is $1 \%$ [7] of the total population of world.

Women, disabled persons and older people are left behind though their population is in billion. Except some of the exceptions, this group of people usually cannot actively participate in social activities, sometimes cannot handle their own activities, and may not be productive members in their family.

There are 17 SDGs(Sustainable Development Goals) defined by United Nations. The goal we are considering in this paper is SGD -3. It states that," Ensure healthy lives and promote well-being for all persons with disabilities ". In this paper we considered the uses of assistive technology to realize goal 3 of SDGs.

Assistive technology is the one which will helps the disabled to overcome their impairments, inequalities and barriers. Assistive products improve the quality of life of the disabled. Assistive technology is the term that covers systems and services related to production and delivery of assistive products and services. Many Assistive products such as hearing aids, pills organizer, artificial limbs, and screen readers have been developed to facilitate the smooth functioning of disabled [8].

Published By:

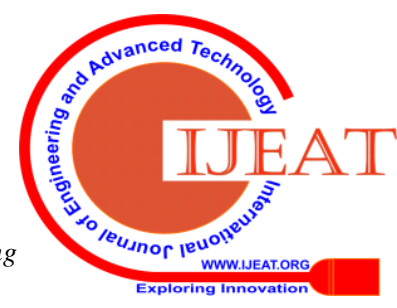


To support countries in their efforts to comply with the CRPD, the World Health Organization (WHO) launched the Global Cooperation on Assistive Technology (GATE) in 2014 in partnership with organizations of and for persons with disabilities; UN agencies, donor agencies, professional organizations, academia and industry. With the SDGs come another international mandate and a platform to further raise awareness and build on existing efforts to improve access.

The objective of this paper is to highlight the status of disabled people in India, Assistive technologies that can improve the well-being of disabled persons, importance of population-wide access to assistive products as a prerequisite for and facilitator of achieving the SDG-3.

\section{STATUS OF DISABLED PERSONS IN INDIA}

Based on Latest census which was reported in the year 2011, Total population in India is the population of India is 121 crore of people, with 623, 724, 248 males and

586,469, 174 females. Among them 2,68 corers are disabled. The disabled status of Indian states is shown in figure 2 .

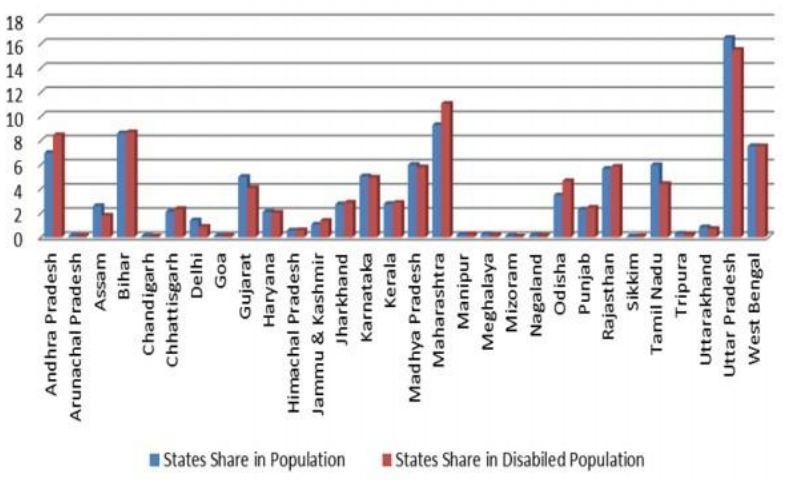

Figure 2:Disabled population share among India states

Out of these 2.68 corers, $56 \%$ of the disable population are male and $44 \%$ are female. It is further reported that major portion of disabled say $69 \%$ are residing in rural areas and the remaining $31 \%$ are residents of urban areas. The percentage of male and female in rural and urban area is shown in is shown in figure 3 .

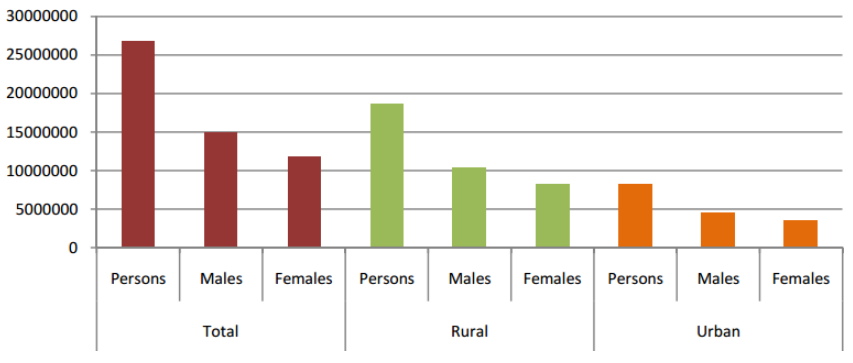

Figure 3: The percentage of male and female in rural and urban area

Sustainable Developmental Goal 3 aims to assure healthy lives and well-beings for all. WHO defined health as "a state of complete physical, mental and social well-being and merely the absence of disease ", and health has social, physical and psychological dimensions. Well-being can be measured based on income, education and health as though it is only the individuals who can realize and express their quality of life. And therefore the factors such as income, education and health can be used some extend to find people's quality of life.

At present the total literacy rate of India is $74.04 \%$. In that only $1.46 \mathrm{cr}$ i.e $55 \%$ out of total population of disabled are literates. Among male disabled persons $62 \%$ are literates and $45 \%$ of female populations are literates, which are shown in figure 4

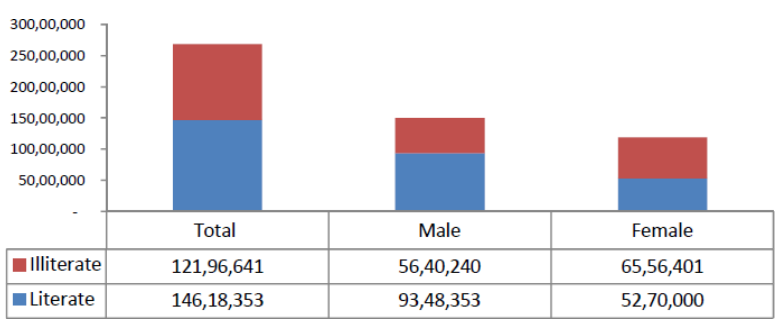

Figure 4:Liteary status of disabled population in India

The type of disability has been categorized as impairment in (i) seeing (ii) hearing (iii) speech (iv) movement (v) mental retardation (vi) mental illness (vii) multiple disability (viii) any other. The persons with various disability in India has been shown in figure 5 .

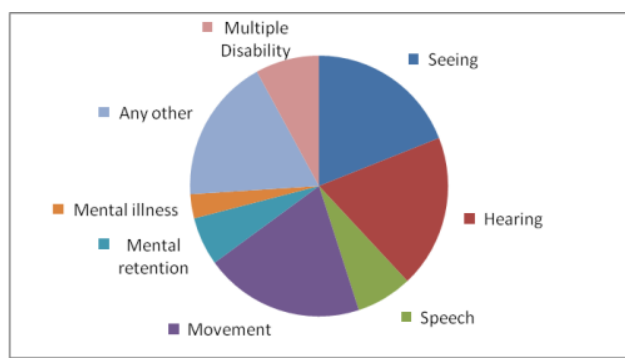

Figure 5: Disability population with various type of disability

The well-being of a disabled person may be influenced by the type and percentage of disability. The level of literacy, employability and income will be affected by the type of disability. For example disabled children may not have a chance to study in the institutions along with others. The literacy rate of children is shown in figure 6.
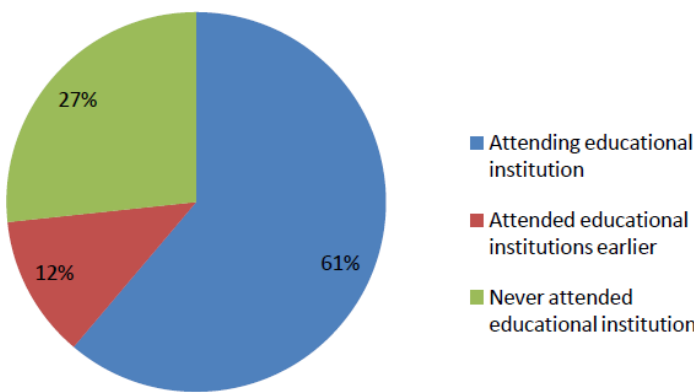

Census data of India 2011, gives a clear picture that nearly one third of the total disabled population are working. Employment status of various disabilities is shown in figure 7. From the figure it is evident that percentage of nonworker group among disabled

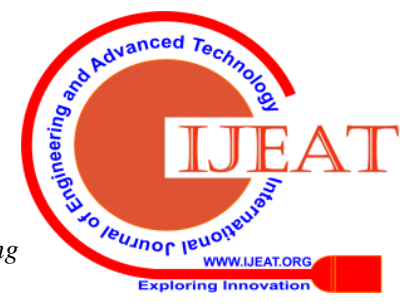


is higher than marginal and main worker. Employability of a person has to be improved in-order to achieve sustainable goals.

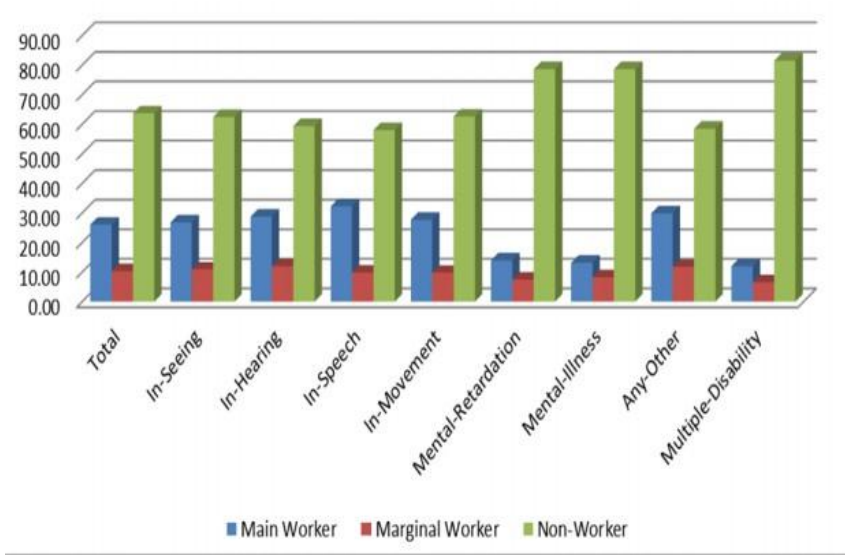

Figure 7: Employment status of various types of disability

Human being is blessed with long life because of the rapid development in medical field. Older people may contribute to the family in many ways provided they are good health. As they age, people will depend on the family members. From the statistical data we can find that among the non-workers $23 \%$ are belong to age group of more than 60 . These un-employed aged persons become depended on the family members. This dependency will create discomfort to both the family members and the dependent. This is the case for all the disabled persons for that matter, regard less of the kind of disability. Assistive technology to some extend comes in handy for those in need of support. In the next section scope and advantages of using assistive technology is discussed.

\section{SCOPE OF ASSISTIVE TECHNOLOGY}

Impact of assistive technology covers health and well-being of a person, helps in improving the socio- economic conditions of human being in various ways. For example, using the hearing aids in the younger age properly will improve the children's language skills, education and employment [9]. Similarly therapeutic footwear reduces the possibilities of getting affected by foot ulcers and lower limb amputations [10]. Use of hearing aids by people with hearing problem and wheelchairs by people with ambulatory impairments, results in reduced poverty in Bangladesh [11]. Augmentation and alternative communication (AAC) products such as touch screen, screen readers, alternative keyboards enable children with severe disabilities to communicate with others and thus improve their social activities [12]. Use of language software and internet helped the students with learning disabilities to learn how to read and write [13]. To improve the productivity and self-esteem [14], better employability and work environment is needed, and which can be ensured by products like adapted telephones, wheelchairs, magnifiers and adapted computer equipments. Proper and timely utilization of the assistive products can improve the independent living and community participation for young adults, even with issues like Spina Bifida [15], which is a birth defect due to malformation of spinal cord. The proud and happy occasions like the UN World conference on disaster risk reduction which had people with impairments as speakers, panelists, contributors in the conference [16].
Collectively, assistive technology helps in

- $\quad$ Getting better Education

- $\quad$ Getting better health

- $\quad$ Support for Caregivers

- Better employability

\section{ROLE OF ASSISTIVE TECHNOLOGIES}

Assistive technologies provide various support to the disabled population. Types of support may be Assistive technology will help in many ways, such as (i) assisting to live, or (ii) to assess the level of disability, (iii) to train disabled to overcome disability.

Table 1 lists some of the assistive product and its type of support

\begin{tabular}{|c|c|c|}
\hline Product & Description & Type of support \\
\hline $\begin{array}{l}\quad \text { (1)Jaws for } \\
\text { Windows } \\
\text { (JFW), } \\
\quad(2) N V D A \text { are } \\
\text { designed for } \\
\text { windows operating } \\
\text { (3)Speakup - for } \\
\text { Linux Operating } \\
\text { system }\end{array}$ & $\begin{array}{l}\text { a screen reader transmits } \\
\text { whatever text is } \\
\text { displayed on the } \\
\text { computer screen into a } \\
\text { form that a visually } \\
\text { impaired user can } \\
\text { process (either as speech } \\
\text { or Braille) }\end{array}$ & Aiding \\
\hline $\begin{array}{l}\text { The Miracle Ear } \\
\text { Digital Hearing Aid }\end{array}$ & Amplify the sound & Aiding \\
\hline Real Speech & $\begin{array}{l}\text { speech analysis program } \\
\text { designed for doing } \\
\text { speech/voice } \\
\text { assessments }\end{array}$ & Assessment \\
\hline $\begin{array}{l}\text { Fonator Speech } \\
\text { Trainer, \& Fonator } \\
\text { Auditory Speech } \\
\text { Trainer }\end{array}$ & Training kit & Training \\
\hline
\end{tabular}

Many software apps are also available to improve the mental health of the disabled.

\section{EXISTING STATUS OF ASSISTIVE TECHNOLOGY}

Assistive product industry is currently serving high income markets only. Following are some of the challenges in this industry are:

\section{$\checkmark \quad$ Lack of proper service and delivery system \\ $\checkmark \quad$ User-centered research and development \\ $\checkmark \quad$ Quality and safety standards \\ $\checkmark \quad$ Appropriate product design}

In order to meet the sustainable development goals, Global Cooperation on Assistive Technology (GATE) developed 4 practical tools to support and coordinate countries for ensuring improve access to assistive technology, wherever and whenever needed.

To help nations in providing and achieving SDGs WHO created Global Cooperation on Assistive Technology (GATE). GATE has launched Priority Assistive Product List (APL) [17] , which contains 50 priority assistive products. To meet the SDGs every nation should have a nation Priority Assistive Product List, Policy to ensure the access of these products by needy such as service provisioning and skilled personnel. 
As per WHO report, Among 75 million people who are in need of wheelchair only 5 to $15 \%$ are having access to it. Similarly, only $10 \%$ global need for hearing aid has been met out of 466 million needy people. Affordability is one of the major issues in low-income countries to have access to assistive technology [18].

Universal health coverage (UHC) implies that all people and community can use promotive, preventive curative rehabilitative and palliative health services they need that is of sufficient quality to be effective while also ensuring that the use of these services does not expose the user to financial hardship[19]. Universal Health coverage can be ensured only when people are able to access quality assistive products as per their needs.

As per 2013 estimate, of 132 low-and middle income countries, only 36 will be able to reach the goal of $5 \%$ spending of gross domestic product(GDP) on health by 2040 [20].

Lack in trained/skilled human resource to provide assistive technology is another important challenge. People of More than $75 \%$ of low-income countries are not having access to prosthetic and orthotics training programmers', in other words lack of skilled persons to train the affected people is one of the issues to be addressed. As far as the India is concerned only 0.7 physicians per 1000 persons and 1.8 nurses/mid wives per 1000 against recommended norms of $1: 1000$ and 4:1000 respectively [21]

The use of information and communication technology (ICT) for bridging the gap of for those lacking access to quality healthcare and reaching the unreached is essential for India which is an IT powerhouse and has the second highest mobile connection globally. Various ICT applications in India includes telemedicine, vaccine and drug inventory control and storage(electronic vaccine intelligence network), training of health workers(ANMOL, m-ACADEMY, safe mother hood), promotion of behaviour change (m-cessation text messaging service) are available [ 22].The Ayushman Bharat scheme has allocated 12 billion in the union budget in 2018 for the upgrading of sub centers into H \& WCs(Health and Wellness centers)[23].

\section{CONCLUSION}

There are many kinds of disabilities. Well-being of a person will be very much affected by these disabilities. Countries like India are planning to attain the sustainable development goals; one among them is ensuring well-being of all. Though well being attributed many subjective things like peace, factors like education status, employability, income can be used to measure well-being of a person to some extent. To facilitate better education, employability of disabled persons, assistive technologies come in handy. This paper discusses some the Assistive technology products. Awareness and affordability, non-availability of skilled persons are the major challenges. Every country should have some plan to include those marginalized person's to achieve sustainable development.

\section{REFERENCES}

1. United Nations Development Programme, "Sustainable Development Goals," 20 August 2016. [Online]. Available: http://www.undp.org/content/undp/en/home/sustainable-developmen t- goals.html.
2. UN General Assembly Resolution (A/RES/65/186, dated: 21 December,2010) https://WWW.un.org/en/ga/65/resolutions.shtml

3. Social Statistical division report, Ministry of Statistics and Programme Implementation, Government of India,http://www.mospi.gov.in

4. United Nations, All governments endeavour to reach " the furthest behind first" ["Sustainable Development Knowledge Platform: Transforming our world: the 2030 Agenda for Sustainable Development ,'2016. [Online]. Available: https://sustainabledevelopment.un.org/post2015/transforming our world.

5. World Health Organization. World report on Disability. Geneva: WHO; 2011

6. UNICEF \& WHO. Assistive technology for children with disabilities: creating opportunities for education, inclusion and participation: a discussion paper, Geneva: WHO; 2015.

7. UNESCO. The Dakar framework for action: education for all.Paris:UNESCO; 2000

8. Khasnabis C, MacLachlan M, Mirza Z. Opening the GATE to inclusion for people with disabilities. Lancet. 2015;386(10010):2229-30

9. Global burden of childhood hearing impairment and disease control priorities for developing countries. Olusanya BO, Newton VE. Lancet. 2007 Apr 14;369(9569):1314-7.

10. Footwear and offloading interventions to prevent and heal foot ulcers and reduce plantar pressure in patients with diabetes: a systematic review. Bus SA, van Deursen RW, Armstrong DG, Lewis J, Caravaggi $\mathrm{CF}$, Cavanagh PR. International Working Group on the Diabetic Foot.

11. Borg J, Ostergren P, Larsson S, Rahman A, Bari N, Khan A. Assistive technology use is associated with reduced capability poverty: a cross-sectional study in Bangladesh. Disabil Rehabil Assist Technol. 2012;7(2):112-21

12. Alquraini T, Gut D. Critical components of successful inclusion of students with severe disabilities: literature review. Int J Spec Educ. 2012;27(1):42-59

13. GAATES: Globalk Accessibility News, "Language assistance software aids students with learning disabilities," GAATES, 2016. [Online]:Available:http://globalaccessibilitynews.com/2016/07/15/la nguage-assistance- software-aids-students-with-learning-disabilities/.

14. Yeager P, Kaye SH, Reed M, Doe TM. Assistive technology and employment:experiences of Californians with disabilities. Work. 2006;27(4):333-44

15. Johnson KL, Dudgeon B, Kuehn C, William W. Assistive technology use among adolescents and young adults with Spina bifida. Am J Public Health. 2007;97(2):330-6.

16. UNISDR,"The United Nations Office for Disaster Risk Reduction,”2015. [Online]. Available: https://www.unisdr.org/archive/43260.

17. World Health Organization. Priority assistive products list. Geneva:WHO; 2016.

18. Users' perspectives on the provision of assistive technologies in Bangladesh: awareness, providers, costs and barriers. Borg J, Ostergren P. Disabil Rehabil Assist Technol. 2015 Jul;10(4):301-8. doi: 10.3109/17483107.2014.974221. Epub 2014 Oct 27

19. World health report. Health Systems Financing: The path to universal coverage. Geneva. World health organization, 2010

20. Dieleman, JL, Templin T, Sadat N, Reidy P, Chapin A, Foreman K et al. National spending on health by source for 184 countries between 2013 \& 2040. Lancet 2016, 387:2521-35

21. Deo MG. Doctor population ratio in India - The reality. Indian Journal Med Res 2013; 137:632-5

22. National Health Portal Mobile Health Apps. Available from https: Ilwww.nhp.gov.in\mobile-app

23. Bharat A. National Health Protection Scheme. Available from https://www.india.gov.in/spotlight/ayushman-bharat-national-healthprotection-mission. 


\section{AUTHORS PROFILE}

Dr. K. Ponmozhi is currently working as Assistant professor in the Department of computer applications, Kalasalingam Academy of Research and Education, Srivilliputhur, TamilNadu, India. She received her Bachelors degree in computer science from Madurai Kamaraj University, her MCA from Bharathidasan University. She received her Ph.D in computer science from Mother Teresa women's University. She has more than 20 years of teaching experiences. She published many articles in journals and conferences both in National level and International Level. Her area of interest is networking, computer graphics, image processing, cognitive science.

Dr. K.Maheswari received her B.sc (Computer Science) from Madurai Kamaraj University and MCA. M.Phil. from Bharathidasan University. She has completed her Ph.d at Bharathiar University. She is currently working as an Associate Professor in the Department of Computer Applications, Kalasalingam Academy of Research and Education. She has 23 years of teaching experience. She has presented research papers in several national and international conferences. She has published many research papers in various international journals. Her research interest is VoIP, network security and Data Mining.

Dr. P. Sriramakrishnan is currently working as an Assistant Professor in the Department of Computer Applications, Kalasalingam Academy of Research and Education, Krishnankoil, India. He received his Bachelor of Science (BSc) in 2011 from the Bharathidasan University, Trichy, Tamil $\mathrm{Nadu}$, India. He received his Master's of Computer Applications (MCA)in 2014 from The Gandhigram Rural Institute - Deemed University, Dindigul, Tamilnadu, India. He worked as a Project Engineer in Dhvani Research and Development Pvt. Ltd, Indian Institute of Technology Madras Research Park, Chennai during May 2014-March 2015.His research focuses on medical image processing and parallel computing. 